\title{
An unusual case of polyembolokoilamania: Urethral avulsion from foreign object use during sexual gratification
}

\author{
Garson Chan, MD; Adiel Mamut, MD; Stephanie Tatzel, MD; Blayne Welk, MD, MSc
}

Department of Surgery, Western University, London, ON, Canada

Cite as: Can Urol Assoc J 2016;10(5-6):E181-3. http://dx.doi.org/10.5489/cuai.3778 Published online May 12, 2016.

\begin{abstract}
Polyembolokoilamania is the insertion of foreign objects into body orifices for sexual gratification. While the retrieval of these objects from the urethra and bladder is a well-known task among urologists, we present a rare case of an usual and serious injury from this practice: complete avulsion of the urethra at the penoscrotal junction. A single-stage urethroplasty was used to reconstruct the urethra with good result. The patient motivation, as well as concomitant medical or psychological conditions, should be explored in order to prevent further occurences.
\end{abstract}

\section{Introduction}

The insertion of foreign objects into the genitourinary tract is commonly reported in the literature and our colleagues in general surgery, gynecology, and otolaryngology also manage these problems (depending on the orifice)..$^{1-3}$ There are many motivations and etiologies, however most are related to sexual satisfaction (polyembolokoilamania). Specifically, for urethral manipulation, this likely leads to prostatic stimulation and activation of hypogastric nerve afferents, leading to sexual pleasure. ${ }^{4}$ This case is unusual due to the resulting injury, which to our knowledge, has not been reported before.

\section{Case report}

A 65-year-old man was transferred from an outside emergency department due to the sudden onset of penile pain, bleeding, urethral "mass or clot" at the meatus, and an inability to void after a urethral trauma. Earlier that evening, he had been self-instrumenting his urethra using plastic tubing for sexual gratification. He had passed the tubing down the urethra, but subsequently had difficulty removing it. He then forcefully removed the tubing, which when removed was found to have an approximately $1 \mathrm{~cm}$ knot at the end. On presentation to the hospital, it appeared that he avulsed a portion of his urethra. His scrotum and penis were swollen and ecchymotic. A $5 \mathrm{~cm}$ portion of intussuscepted penile urethra was attached to the glans and bleeding (Fig. 1). The patient was consented for surgical exploration, possible urethral repair in a single or multistage manner, or potentially a perineal urethrostomy. A suprapubic catheter was placed prior to operative management.

Intraoperatively, we confirmed the diagnosis by examining the protruding portion of urethral tissue. The edge was grasped with a Babcock and the urethral intussception reduced (Fig. 2A). A penoscrotal incision was made; dissection was carried down to the end of the Babcock and the distal end of the bulbar urethra identified. Care was taken to minimize trauma to surrounding skin and fascia layers. The urethral viability was confirmed with active bleeding and blanching and filling of the spongiosum with pressure. Cystoscopy was carried out, which showed false passages and mucosa damage at the level of the prostatic urethra and a normal bladder without any retained foreign bodies. The penile urethra appeared to have separated from the corporal bodies and bucks fascia with minimal trauma and the peno-glandular urethral junction was intact. Consideration was given to a staged repair, however, the urethral tissue appeared to be healthy and a single-stage procedure was felt to minimize morbidity and provide maximal salvage of the urethral plate tissue. The proximal portion of the penile urethral plate was split in half from the injury (Fig. 2B). This was repaired in two layers using 5-0 moncryl. The edges of the penile and bulbar urethral were then freshened and a two-layer closure undertaken using 5-0 monocryl (Fig. 2C). A 16 French urethral catheter and a drain were left. The patient was discharged home on postoperative Day 1 with the suprapubic and urethra catheter draining. At six weeks postoperative, a retrograde urethrogram (RUG) did not show any evidence of extravasation and his urethral catheter was removed. His suprapubic tube was removed a 


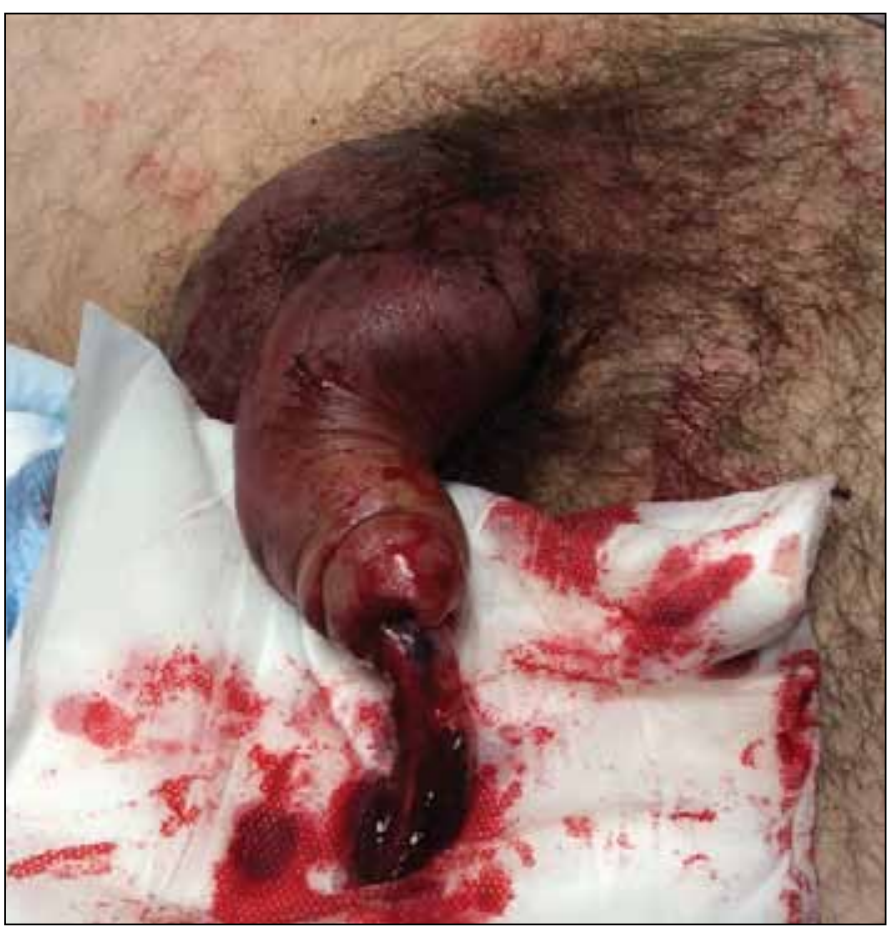

Fig. 1. Appearance of intussuscepted urethra at presentation.

week later after a trial of clamping for two days. After four weeks of normal voiding without catheters, a second RUG demonstrated an intact urethra with some narrowing of the proximal penile and penoscrotal urethra (Fig. 3). A 16 French flexible cystoscope could be advanced easily through the urethra. He did not report any voiding complaints and had achieved erections without significant chordee.

\section{Discussion}

There are a wide range of self-inflicted injuries involving the genitourinary tract from foreign bodies that are inserted either traumatically, accidentally, or intentionally..$^{1-3,5,6}$ The actual prevalence of this practice is unknown, due to the nature of the event. Many patients repeat this behaviour and even the development of complications and hospitalization may not be enough to stop this activity. ${ }^{6,7}$ Delayed presentation is common due to embarrassment and may result in further injury, complications, and migration. Usually, the symptoms of foreign body insertion include hematuria, pain, retention, infections, or voiding dysfunction. The diagnosis is based on the patient offering a candid history, radiologic exams, or cystoscopy. Complications may include mucosal tears, false passages, stenosis, infection, abscess, pain, erectile dysfunction, fistula formation, and further lower urinary tract symptoms. ${ }^{1-3,5,8}$ After the acute urological problem is managed, the motive and underlying etiology should also be considered. Medical and psychosocial issues often exist, which require further assessment. The etiology of polyembolokoilamania may be related to medical conditions, such as mood and cognitive disorders, drug abuse, malingering, or most commonly sexual gratification.

In this case, recognition that the extruding urethral mass was viable urethral tissue and not clot, as well as a careful and prompt surgical repair provided an excellent cosmetic and functional result. While a ureteral avulsion is a rare but dreaded complication of ureteroscopy, ${ }^{9}$ avulsion has not, to our knowledge, been described for the urethra. If there had been more extensive loss of urethral tissue, a staged procedure with a temporary penoscrotal opening

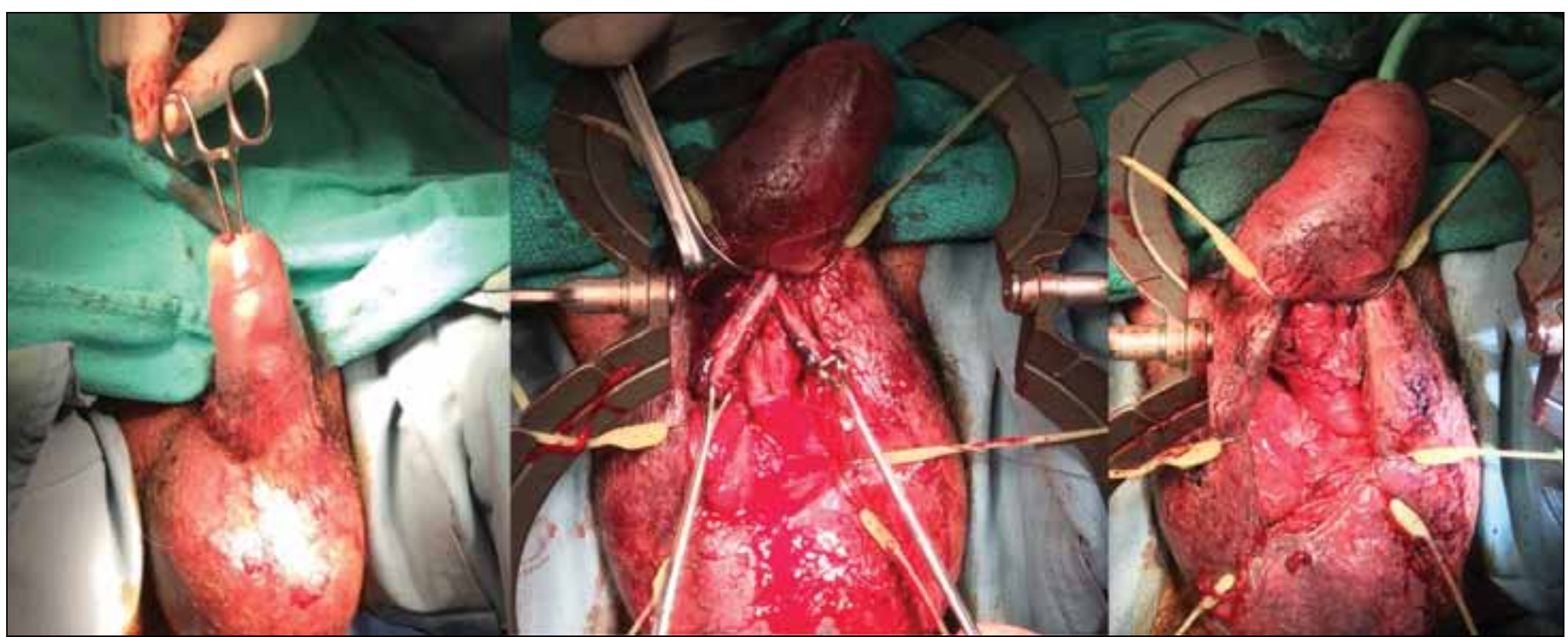

Fig. 2. Intraoperative appearance of: (A) the urethra reduced into place using a Babcock; (B) the partially split urethral plate at the penoscrotal junction held by Babcocks; and (C) the repaired urethra. 


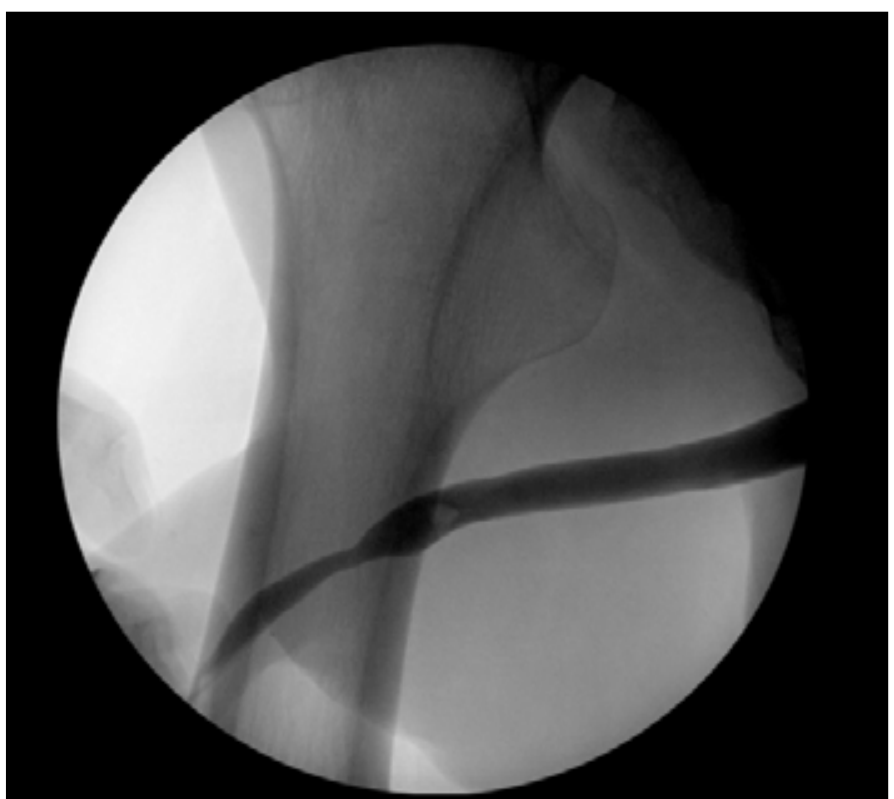

Fig. 3. Retrograde urethrogram eight weeks after the injury (four weeks postcatheter removal).

would have been appropriate. This patient is still at risk of developing a symptomatic urethral stricture, however, the preservation of the majority of the urethral plate and minimal disruption to the tissue and blood supply of the surrounding penile and scrotal skin with this single-stage procedure should maximize the operative possibilities should he need a future urethroplasty. He was counseled about the risks of future self-urethral instrumentation, referred to his family physician for psychiatric care, and followup will be carried out to monitor for voiding dysfunction.

\section{Conclusion}

We describe the successful single-stage management of an emergent urologic presentation of a urethral avulsion as a result of a self-stimulation with rubber tubing.

Competing interests: Dr. Welk has participated in clinical trials for Astellas. The remaining authors declare no competing financial or personal interests.

This paper has been peer-reviewed.

\section{References}

1. van Ophoven A, deKernion JB. Clinical management of foreign bodies of the genitourinary tract. J Urol 2000;164:274-87. http://dx.doi.org/10.1016/S0022-5347(05)67342-9

2. Walsh $P$, Moustafa M. Retention of urethrovesical foreign bodies: Case report and literature review. J Emerg Med 2000;19:241-3. http://dx.doi.org/10.1016/S0736-4679(00)00232-8

3. Wenderoth U, Jonas U. Curiosity in urology? Masturbation injuries. Eur Urol 1980;6:312-3.

4. Komisaruk BR, Beyer-Flores C, Whipple B. The Science of Orgasm. Published by Hopkins Fulfillment Service, 2006.

5. Granados EA, Riley G, Rios GJ, et al. Self-introduction of urethrovesical foreign bodies. Eur Urol 1991;19:259-61.

6. Costa G, Di Tonno F, Capodieci S, et al. Self-introduction of foreign bodies into the urethra: A multidisciplinary problem. Int Urol Nephrol 1993;25:77-81. http://dx.doi.org/10.1007/BF02552258

7. Unruh BT, Nejad SH, Stern TW, et al. Insertion of foreign bodies (polyembolokoilamania): Underpinnings and management strategies. Prim Care Companion CNS Disord 2012;14:1. http://dx.doi.org/10.4088/ pcc. $11 f 01192$

8. Rahman NU, Elliott SP, McAninch JW. Self-inflicted male urethral foreign body insertion: Endoscopic management and complications. BJU Int 2004;94:1051-3. http://dx.doi.org/10.1111/i.1464410X.2004.05103.X

9. Tanimoto R, Cleary RC, Bagley DH, et al. Ureteral avulsion associated with ureteroscopy: Insights from the MAUDE database. J Endourol 2016;30:257-61. http://dx.doi.org/10.1089/end.2015.0242

Correspondence: Dr. Blayne Welk, Department of Surgery, Western University, London, ON, Canada; bkwelk@gmail.com 